\title{
7 Bisexual women and monogamy
}

\author{
Sarah Jane Daly
}

\section{Introduction}

In contemporary Western society, bisexuality has increasingly become recognised as a legitimate and valid sexual identity. However, there are inevitable tensions between bisexual identity and monogamy. This chapter explores these tensions by drawing on historical and contemporary research. Previous research has tended to concentrate on monogamy from a mononormative perspective, focusing on heterosexual and/or homosexual relationships. Consequently, the experiences of bisexual women and monogamy have received little attention from researchers. This chapter begins with a review of the bisexual literature in a bid to outline a more in-depth and focused description and understanding of both the historical and contemporary perspectives of bisexuality as an accepted sexual identity and orientation. The author then discusses the ways in which monogamy has been conceptualised historically before moving on to briefly present contemporary views of monogamy in Western society. The chapter then focuses specifically on bisexual women and monogamy. In particular, this chapter draws from the current literature specifically related to the challenges faced by bisexual women when they are involved in a monogamous relationship.

\section{Binary understandings of sexuality}

Sexuality has been conceptualised in binary terms for well over a century (Callis, 2014). "The elephant in the room" is a metaphor used to illustrate how discussions and representations of bisexuality are kept on the fringes of the sexuality binary (Hartman, 2006). The binary is exhaustive in the sense that at one end it is exclusively heterosexual and at the other it is homosexual. Thus, sexualities that do not fit into those contested categories are rendered mute and invisible (Anderson, McCormack, \& Ripley, 2016; Klesse, 2006). The binary opposites both reify and strengthen one another in the respect that they are hinged on each other's continuation in order to exist (Namaste, 1994). One of the problems when attempting to conceptualise oneself outside the binary is the resulting ethereal space one inhabits (Daly, 2018). 
Callis (2014) uses the metaphor of the "borderlands" to illustrate nonnormative identities. This concept originated from the work of Anzaldúa (1987), who attributed it to individuals who lived on, and crossed over, the border between Mexico and the United States. Anzaldúa (1987, p. 243) notes the liminal space these people occupied, referring to it as "an unstable, unpredictable, precarious, always in transition space lacking clear boundaries". Callis (2014) notes the similarities between the individuals Anzaldúa describes and those who hold plurisexual identities. Both groups can be seen to be on the border of two dominant power-houses: heterosexual and homosexual, Mexico and the United States. Both groups are betwixt and between, not fitting in to either/or. Callis, $(2014$, p. 69) argues that, just like the individuals discussed by Anzaldúa (1987), bisexual people and other plurisexual identified people are "caught between two communities and two labels".

One could argue that to understand bisexuality, one has to refer to the binary of monosexuality. Bisexuality, then, can be seen to hold the potential to problematise the binary and break down assumptive discourses related to sexual orientation and identity (Stein \& Plummer, 1994). The lesbian feminist and gay liberation movements of the mid- to late twentieth century were constructed in terms of an oppressed minority struggling against a heterosexual and patriarchal majority. One of the unintended consequences of this struggle was the acceptance in everyday discourse that there are only the dominant oppositional sexualities. More recently, identity categories such as bisexual, transgender, and transsexual have been acknowledged and have become considerably more visible (Maliepaard, 2017).

\section{Historical conceptualisations of monogamy in Western society}

Views about the nature of monogamy in Western society - particularly monogamy through the sanctioned institution of marriage (Rust, 2003) - position the monogamous dyadic relationship as the most successful and valid type of relationship (Green, Valleriani, \& Adam, 2016). The monogamous dyad is also considered the site in which the needs of both partners can be met, albeit not easily and not without some degree of commitment and work. This is, however, a relatively modern conception of monogamy and is somewhat different from constructions of monogamy historically and in other cultures (Barker, 2011; Giddens, 1992).

In the late Victorian era, Von Krafft-Ebing (1894) proposed the view that sexual desire is something that needs taming - particularly in men - as it is dangerous if left to its own devices. He argued that morality tames the explosive nature of sexual desire and that monogamy sets some boundaries on this power. Von Krafft-Ebing (1894, p. 5) states that

the fact that in higher civilization human love must be monogamous and rest on a lasting contract was thus recognized. If nature does not more than provide for procreation, a commonwealth (family or state) 


\section{Sarah Jane Daly}

cannot exist without a guarantee that the offspring shall flourish physically, morally and intellectually ... establishing monogamous marriage and securing it by legal, religious and moral ties.

Von Krafft-Ebing's (1894) message is clear; in order to secure a stable future for children, parents ought to engage in a monogamous relationship. Monogamy for men is a moral and respectable way in which their sexual needs can be met. Von Krafft-Ebing (1894) also argued that women did not experience sexual desire in the same way as men. Women's desire is to be understood as being focused predominantly on love, rather than being driven by sexual desire. This enabled women to be positioned as persons who served the needs of their husbands and cared for their children.

The views of Von Krafft-Ebing (1894) were influential through the early part of the twentieth century, but have received a critical reception from academics more recently. For example, Savoia (2010) argues that Von KrafftEbing (1894) was instrumental in creating a set of myths about women that contributed to their subjugation. In a similar vein, Szasz (1980, p. 45) states:

Von Krafft-Ebing ... was not interested in liberating men and women from the shackles of sexual prejudice or the constraints of anti-sexual legislation. On the contrary, he was interested in supplanting the waning power of the church with the waxing power of medicine.

On the other hand, Oosterhuis (2012) argues that Von Krafft-Ebing modernised sexuality and, despite his Christian views in relation to gender roles, did advocate the view that men and women were equals.

Coontz (2005) maintains that it was not until the 1950s that the majority of people in Western society could afford to marry for reasons of love and sexual desire. Although the moral superiority of monogamy was challenged by some writers in the Victorian era, by the mid-twentieth century the dominant discourse was that marriage and monogamy were "normal". This also resulted in monogamy being conceptualised as the "traditional" relationship practice, which was far from being an accurate representation of social history. The 1960s marked a generational shift in attitudes towards relationships and extra-marital sex (Edmunds \& Turner, 2005). The contraceptive pill was released in the United Kingdom in 1961 - initially to married women only, before becoming available to all in 1967 (Bridge, 2007). This social change, alongside others, such as the improvement of women's position in the workplace (Goodson, 2001), marked a shift in the way sex and relationships were perceived. Feminists saw this development as freeing women up to engage in consensual sex without the fear of an unwanted pregnancy. In addition, many feminists, especially radical lesbian feminists, saw this medical advance as an opportunity for women to challenge heterosexual patriarchy and advocated a reconceptualisation and redefinition of practices such as monogamy (Summerfield, 1994). The late 1960s and 
1970s could be seen as a time of sexual and social experimentation, with women questioning taken-for-granted assumptions about their social and relationship roles and behaviours. This led to many feminists choosing to reject monogamy in their intimate relationships. However, by the 1980s, and in the throes of the HIV and AIDS epidemic, many feminist heterosexual women returned to monogamy as they reported experiences of being treated disrespectfully by their male partners, and fearing potential sexual infection (Bindel, 2013). For many same-sex attracted people, claims related to nonheterosexual people being in better positions to "construct their relationships from scratch" (Heaphy, Donovan, \& Weeks, 2004, p. 168) were sidelined in favour of practising their relationships in the same fashion as the majority of heterosexuals: in a monogamous dyad. The monogamous couple relationship continued to be central to social life, with romantic films, songs and family politics reinforcing the monogamous, mononormative relationship arrangement (Ahmed, 2010). Sexual exclusivity in intimate relationships became positioned as the normal and moral way in which to live out one's love relationship.

Historically, then, we have a picture of monogamy as a concept that has changed over time. The Victorian era marked a shift in views from a tolerance of non-monogamy evident in the eighteenth century to a position that saw monogamy as an essential component of a relationship. The idea that sexual desire was different for men and women was actively promoted by the scientific community towards the end of the nineteenth century (e.g. Von Krafft-Ebing, 1894). This set the scene for the development of ideologies around relationships and sexuality that dominated the first half of the twentieth century and beyond.

\section{Contemporary views on monogamy}

Despite the changes in views and beliefs about sexuality and relationships, monogamy is still considered an important social norm. Findings from the National Survey of Sexual Attitudes and Lifestyles (NSSAL) (Erens et al., 2003) show that monogamy continues to be considered important in committed relationships and/or marriages, with 77 per cent of men and 85 per cent of women reporting that sex outside of a relationship is wrong. Although large-scale social surveys, such as the NSSAL, are valuable sources of information about general social views and attitudes, they are not able to explore issues in detail. They do not, for example, provide any insights into the reasons why respondents consider infidelity to be "wrong".

Green, Valleriani and Adam (2016) carried out a study that explored contemporary views on monogamy in depth. Their participants were predominantly white and identified as heterosexual, gay, or lesbian. In response to questions about monogamy, participants' attitudes generally fell into two broad groups: those who took a "normative approach" and those who took a "reflexive approach" (Green, Valleriani \& Adam, 2016, p. 422). The 
"normative" group expressed the view that there was little point getting married or committing to a monogamous relationship if their partner behaved in non-monogamous way. In other words, this group valued the principles of monogamy and were prepared to commit to these values in a relationship. The "reflexive" group expressed the view that what individuals do in the context of their own relationships is up to them. In other words, their values and beliefs were less constrained by social norms and ideologies.

Green, Valleriani and Adam (2016) went on to look at how their participants conceptualised monogamy within their own relationships and again identified two broad groups: "structured" and "plastic" (Green, Valleriani \& Adam, 2016, p. 422). The "structured" group believed that, while non-monogamous practices might be acceptable for other people, they were not drawn to conducting their intimate relationship in that way, preferring to follow a "normative" approach to relationships. Those in the "plastic" belief group were more open to the possibility that sexual activity outside the context of their relationship was something that would have to be considered and negotiated, but they were not directly opposed to it.

What is particularly interesting about this particular piece of research is that it presents evidence that heterosexual, gay, and lesbian participants hold different attitudes towards monogamy. Heterosexual participants - particularly women - while professing to accept how other people constructed their relationships as being unproblematic, were themselves less likely to implement any alternative behaviours in their own relationships. In part, this may be due to social norms of monogamy and coupledom in relationships (particularly normative heterosexual ones) being so pervasive that implementing changes in one's own relationship presents too challenging a prospect to consider. It is also reasonable to suggest that women face particularly negative judgements with respect to their sexuality and behaviours more generally (Bindel, 2013); thus, to carry out their love/sex relationships in a non-monogamous fashion might well be framed as unfeminine and immoral.

According to Green, Valleriani and Adam (2016), this finding demonstrates that heterosexual people are tolerant to those who choose to lead their relationships in a "plastic" fashion, while at the same time holding an "it's ok for you, but not me" attitude. Lesbian and gay participants were much more likely to opt for a plastic belief position, in that they (particularly gay men) were seen to engage in open dialogue with their partner in relation to meeting each other's sexual and emotional needs. Green, Valleriani and Adam (2016) concluded that, in relation to monogamy, heterosexual people were much less critical of the institutional practice and took an explicit positive stance toward monogamy. However, their gay and lesbian counterparts could be seen to take a more pragmatic approach to monogamy, implying more discussion related to the relationship style effectively being fit for their purpose.

An important methodological point in relation to Green, Valleriani and Adam's (2016) research is that a number of participants were interviewed 
alongside their partners. Although some research espouses the positive aspects of interviewing couples together to enable richer data generation (see Bjørnholt \& Farstad, 2014), it has also been argued that the presence of a partner can influence (both positively and negatively) what is expressed (Valentine, 1999). Nevertheless, their research does demonstrate that beliefs about monogamy vary across different groups in society.

Barker (2011) argues that views about monogamy are typically implicit in relationships, and overt discussions about the subject are relatively rare. A monogamous relationship requires couples to ensure that others are "kept out", which is reflected in social norms relating to the notion that couples have "couple time" on their own. Social norms such as this support an ideology that finding a partner and engaging in a monogamous relationship is the path to a happy life. Gotta and colleagues (2011) conducted research in the United States, drawing on a range of professed sexual orientations, including heterosexual, gay, and lesbian, comparing couples' aspiration for a monogamous relationship. Their findings suggest that couples in the year 2000 desired and engaged in monogamy more than couples did in 1975. This appears to indicate that monogamy continues to be a desired form of relationship. It is nevertheless interesting to note that the researchers received responses from only one member of the couple relationships; thus, surveying or interviewing individuals may lead to different outcomes as compared with interviewing individuals when the partner is present. It is also plausible to consider the suggestion that a greater awareness of diseases such as AIDS and other STIs has led to a more active focus on healthcare behaviours (Moors, Matsick, \& Schechinger, 2017). Gotta and colleagues (2011) present evidence that monogamy agreements between all couples, irrespective of sexual identity, were more explicit in 2000 than they were in 1975. This may reflect changes to the legal and social rights afforded to individuals in the United States between 1975 and 2000. In 1975, civil unions were not available to same-sex attracted people, but by 2000 some states in the United States sanctioned them, which may have some influence on the desire for, and views on, monogamous relationships.

Warner (1999, p. 74) argues that positioning monogamy as the most important relationship practice serves to encourage "damaging hierarchies of respectability", framing alternative relationship styles such as polyamory as inferior (Pieper \& Bauer, 2005). Little attention has been paid to relationship practices that lie outside monogamy, despite growing numbers of people professing to be engaged in consensual non-monogamy (CNM) (Barker, 2011). In a review of the monogamy literature Moors, Matsick and Schechinger (2017, p. 677) suggest that, irrespective of sexual identity, people in modern Western society express moderate to high positive attitudes towards "a hypothetical willingness to engage in different types on consensual non-monogamy". It is important to note that many of the studies on which Moors, Matsick and Schechinger (2017) draw are taken from convenience samples and are cross-sectional in design, making it difficult to 
determine whether this view is transitory and/or likely to change over time. In addition, because participants are responding to a hypothetical scenario, they may well be appraising a situation favourably precisely because they are not currently experiencing this relationship arrangement.

It is clear that the ideology of monogamy remains dominant in twentyfirst century Western society. Monogamy continues to be thought of as a practice that provides individuals with both security and safety. Therefore, the ideology of monogamy retains its position at the top of the relationship hierarchy.

\section{Monogamy and bisexual women: Myths and realities}

The influence of gender, and more specifically identifying as a bisexual woman, brings with it a number of specific binegative assumptions related to both character and behaviour (Callis, 2014):

When I think of 'bisexual' I think of bedhopping ... they not only can't commit to being one or the other, but probably can't commit to whoever they're with, be it male or female. How could someone who wants to be in a long-term committed relationship still call themselves bisexual ... without some infidelity coming into the picture?

(Ault, 1994, p. 117)

This quote succinctly encapsulates one of the common myths faced by bisexual women, particularly with respect to the assumption that bisexual women are more likely to be hyper-sexual than men (Lahti, 2015). There is a belief that the very nature of bisexuality makes it impossible to maintain a monogamous relationship (Callis, 2014). To a large extent, this is based on the assumption that women who claim a bisexual identity are unable to practise monogamy because they are assumed to be naturally promiscuous (Chmielewski \& Yost, 2013). A set of negative stereotypes appears to be associated with the sexual behaviour of women who identify as bisexual. One of the consequences of these stereotypes is that bisexual women who do practise monogamy feel invisible, since they are assumed not to exist in the first place (Hartman-Linck, 2014). Occupying a dyadic relationship, particularly one that is monogamous, brings with it a sense of invisibility with respect to one's bisexual identity in both heterosexual and homosexual communities (Bowes-Catton \& Hayfield, 2015).

The myth of the "promiscuous bisexual" clearly contributes to the view that bisexual women are incapable of securing and retaining a monogamous relationship. This belief seems to be rooted in a binary construction of sexuality that, by definition, excludes the whole concept of a distinct and separate "bisexual" identity. Attempting to conceptualise bisexuality within a binary system results in some form of part-heterosexual, part-homosexual hybrid, which in turn leads to further mythical beliefs, such as that bisexual 
people are in a state of internal psychological conflict because they are unable to satisfy their sexual desires (Diamond, 2008). In other words, the assumption is that if a bisexual person is in a relationship with a person of a different sex, they will have a need for sexual and/or intimate connections with a person of the same sex. If they have committed to a monogamous dyadic relationship, then this assumed need is not likely to be met and as such they are thought to be in a state of internal conflict (Roberts, Horne, \& Hoyt, 2015).

It has been argued that the common characteristic of bisexual people "is their refusal to practice gendered exclusivity" (Rust, 1995, p. 241), which positions them as insecure and untrustworthy (Flanders, Dobinson, \& Logie, 2015). The perception that entering into a monogamous relationship with a bisexual person would present real challenges is pervasive. Eliason (2000) found that 75 per cent of participants who took part in her research preferred not to date a person who identified as bisexual, partly due to the stereotypical belief that the person could not be faithful and would no doubt leave them for someone of a different sex. Vrangalova, Bukberg, and Rieger (2014) further support this finding in that those who have stigmatised identities, such as bisexual people, report finding it more problematic to secure a relationship. Bradford (2004) also concluded that her participants were concerned they could not attain a romantic relationship because they identified as bisexual and were hyper-aware of how they were positioned in society, making it a barrier to finding someone to be with.

Hartman-Linck (2014) explored the lives of bisexually identified women in monogamous different-sex relationships and found that participants engaged in a number of strategies, such as reading LGBT+ orientated literature, in an attempt to keep their bisexuality alive. Participants were considered to be monogamous if they met two criteria: they had to have been in a relationship for at least a year, and in the last 12 months they must only have had sex with their partner. One of the problems with this definition is that it perpetuates the view that physical monogamy is more important and valued than other forms of monogamy. Anderson (2010) points out that monogamy can be defined in a number of ways, but the belief that monogamy means "no sex outside the relationship" remains a dominant social norm (Fisher, 2010).

There are conflicting views about the extent to which bisexual women desire a monogamous relationship. Some research (see Rodríguez-Rust, 2000) seems to suggest that bisexual women are more likely than other sexual orientations to desire a non-monogamous relationship. Other research argues that bisexual women prefer a monogamous dyadic relationship compared with other relationship forms, such as polyamory (Rust, 1995). It seems to be the case that for some bisexual women, having concurrent relationships with people of the same and different sex represents a way in which they feel that they are truly living out their bisexuality (Moss, 2012). One of the ways in which this lifestyle may be achieved is to have 
discreet affairs with someone who is of a different sex from one's current partner. Clearly this course of action is abhorrent to many bisexual people, as it involves deception and dishonesty, and confirms stereotypical views of bisexual people as not to be trusted (Klesse, 2007). There is no doubt that some bisexual people engage in sexual and romantic relationships with people of the same and different sex concurrently (as do other sexualities such as gay, lesbian, and heterosexual), but many bisexual people prefer to opt for monogamous relationships (Toft \& Yip, 2018). This is a view supported by Diamond (2008), who concludes that women who identify as bisexual are more likely than self-identified lesbian and unlabelled women to actively desire and reside in a monogamous relationship. This finding contradicts the pervading stereotype that positions bisexual women as unable to be monogamous. The reality is that some bisexual people (alongside all other sexual orientations) choose to practise monogamy, whether serially or with one person "forever".

\section{Monogamy and bisexual invisibility}

It is argued here that monogamy contributes to bisexual invisibility and marginalisation. Moss (2012) explored the experiences of plurisexually identified women (including bisexual and pansexual women) who were married to men and in a relationship with a woman at the same time. She uses the term "doing bisexuality" (Moss, 2012, p. 406) to describe the practice of physically "doing" or engaging in relationships with people of the same and different sex. Moss (2012) argues that this is one way in which married women can be visible, as they are able to express their bisexuality as well as disrupt ideas around the family and monogamy. This is problematic because it suggests and reinforces the notion that being in concurrent relationships with people of the same and different sex is the only legitimate way to claim the identity label of bisexual. Consequently, those bisexual women who choose monogamy are more likely to have one aspect of their identity - their sexuality - marginalised and invisible to others.

The concept of sexual subjectivity, which Tolman (2002, p. 5) defines as "the experience of oneself as a sexual being who feels entitled to sexuality and sexual pleasure and sexual safety", is also relevant to discussions of marginalisation. Sexual subjectivity is considered important in the context of one's self-esteem in that a person's sexual identity has an impact on how they navigate their way through the world. Given that women and girls are brought up in a patriarchal society, it is vital that their sexualities and their bodies are not rendered "silent" (Tolman, 2002). Bisexual women who are in monogamous relationships with men may well experience their sexual subjectivity differently from those in relationships with women. Feminists argue that positive sexual subjectivity is particularly challenging for women to construct, regardless of sexuality, because they grow up in a sociocultural environment where their sexuality is policed by men; as a result, they tend 
to conceptualise their sexuality from a male perspective (Horne \& ZimmerGembeck, 2006). Women occupy a heteronormative and mononormative world that positions them as heterosexual if their partner is someone of a different sex. If their partner is of the same sex, then women continue to be assumed potentially available to men as their sexuality is often considered performative for men (Fahs, 2009). The consequence is that whether a woman is in a monogamous different-sex or same-sex relationship, her bisexual identity remains hidden (Barker, 2011).

Whenever a bisexual woman enters into a monogamous relationship with a man, her non-normative sexual identity is more or less hidden from the world. Clearly, in some cases others may be aware of an individual's sexual identity; however, there is still the potential for it to become overlooked and invisible. For example, being in a monogamous relationship with a man can lead to claims from others that a woman's bisexuality was a "phase" she was going through, or perhaps that she was doing it to seek out the attention (Daly, King, \& Yeadon-Lee, 2018). Monogamy presents more challenges to bisexual people than to people of other sexual identities in relation to invisibility. A bisexual woman who has children and is in a monogamous relationship with a man is to the onlooker, assumed to have a heterosexual identity (Moss, 2012), as she is defined according to the gender of her partner; thus, her bisexual identity is rendered invisible. When a bisexual woman enters into a monogamous relationship with a woman, she faces similar challenges, with the additional consequences associated with moving away from heteronormativity. Being in a relationship with a woman brings with it the additional pressure and expectations to accept a lesbian identity and to no longer consider oneself as a bisexual woman (Daly et al., 2018). This set of expectations may not come directly from her partner, but instead be levelled at her from the wider lesbian community (Callis, 2014). This situation has been likened to a "tightrope walk", in which a bisexual woman in a relationship with another woman has to balance the pros and cons of expressing her bisexual identity (Anderson et al., 2016). Perhaps it is indeed only through verbal statements that women can be confident that their bisexuality is known (Maliepaard, 2017).

Wiley and Deaux (2010) argue that visibility in relation to one's sexual identity is important, and contributes to the extent to which individuals feel connected to others as well as a means by which they can become involved in social action. One of the challenges faced by bisexual women is that there are no universal physical appearance norms that specifically signify bisexuality (Hayfield, 2011). Research found that one challenge faced by bisexual women when occupying a monogamous relationship, irrespective of the gender of their partner, is a feeling of identity invisibility both within wider heteronormative society, and also within the LGBT+ community (HartmanLinck, 2014). This invisibility manifests in different ways according to the gender of the women's partners. For example, those in same-sex relationships acknowledge that at times disclosing the gender of their partner results in 
others assuming they are a lesbian. This misappropriation has both negative and positive consequences for these women. Access to and, more importantly, acceptance in lesbian spaces and places appears to be one of the advantages of not expressing one's attraction to more than one sex. However, at the same time, an awareness that their bisexuality remains hidden has personal repercussions for them in terms of their self-esteem. Often these women experience feelings of anxiety and guilt for not disclosing their bisexuality. It is also the case that those women in different-sex relationships are aware of the heterosexual privileges associated with being partnered with a person of a different sex (Daly et al., 2018).

\section{Conclusion}

It is argued in this chapter that in contemporary Western society conceptualisations of monogamy are culturally ingrained into our relationship practices. Despite the practice of monogamy being problematic for some individuals (Toft \& Yip, 2018), it is clear that monogamy is the most favoured sanctioned relationship practice in Western society. We can see that monogamy is institutionalised in our everyday lives through institutions such as marriage (Finn, 2012). Although a number of people happily practise CNM and report their relationships to be satisfying, many of them go on to enter into monogamous relationships (Jones, 2016). The culturally constructed ideology of monogamy permeates our everyday lives through narratives of such concepts as "love", and finding one's "soulmate", as well as media depictions that position monogamous relationships as the most appropriate form. These discourses present us with what we understand to be the path to happiness and fulfilment. Despite the cultural inculcation of monogamy, it is important to acknowledge that monogamy is important to many people, irrespective of sexual identity. Monogamy represents and provides people with a sense of security and stability. The research related to how bisexual women in monogamous relationships negotiate their lives and experience their bisexual identity is relatively under-investigated (Daly et al., 2018). Research has pointed to the ways in which bisexual women may struggle with feelings of marginalisation and invisibility as a result of engaging in a monogamous relationship because their sexual identity is assumed to reflect the gender of their partner and relationship arrangement (Moss, 2012). It is important to consider the ways in which bisexual women experience their sexual subjectivity when they are engaged in a monogamous relationship, as research highlights the ways in which all women are inculcated into patriarchal society, which conceptualises their sexuality as a response to male sexuality. Bisexual women who are in monogamous same-sex relationships are therefore engaged in sexual relationships that do not include the participation of men, so they may well experience their bisexual identity somewhat differently from bisexual women in differentsex relationships and those who are not in an intimate relationship. 


\section{References}

Ahmed, S. (2010). The promise of happiness. London: Duke University Press.

Anderson, E. (2010). At least with cheating there is an attempt at monogamy: Cheating and monogamism among undergraduate heterosexual men. Journal of Social and Personal Relationships, 27(7), 851-72. doi: 10.1177/0265407510373908

Anderson, E., McCormack, M., \& Ripley, M. (2016). Sixth form girls and bisexual burden. Journal of Gender Studies, 25(1), 24-34. doi: 10.1080/ 09589236.2013 .877383

Anzaldúa G. (1987). Borderlands/La Frontera. San Francisco, CA: Aunt Lute Books.

Ault, A. (1994). Hegemonic discourse in an oppositional community: Lesbian feminists and bisexuality. Critical Sociology, 20(3), 107-22. doi: 10.1177/ 0896205402000306

Barker, M. (2011). Monogamies and non-monogamies: A response to "the challenge of monogamy: Bringing it out of the closet and into the treatment room" by Marianne Brandon. Sexual and Relationship Therapy, 26(3), 281-287. doi: 10.1080/14681994.2011.595401

Bindel, J. (2013). Rebranding polyamory does women no favours. The Guardian, 26 August. Retrieved from www.theguardian.com/commentisfree/2013/aug/26/ polyamory-no-favours-for-women

Bjørnholt, M. \& Farstad, G.R. (2014). 'Am I rambling?' on the advantages of interviewing couples together. Qualitative Research, 14(1), 3-19. doi: 10.1177/ 1468794112459671

Bowes-Catton, H., \& Hayfield, N. (2015). Bisexuality. In C. Richards \& M. Barker (Eds.), The Palgrave handbook of the psychology of sexuality and gender (pp. 4259). London: Palgrave Macmillan.

Bradford, M. (2004). The bisexual experience: Living in a dichotomous culture. Journal of Bisexuality, 4(1/2), 7-24. doi: 10.1300/J159v04n01_02

Bridge, S. (2007). A history of the pill. The Guardian, 20 September. Retrieved from www.theguardian.com/society/2007/sep/12/health.medicineandhealth

Callis, A.S. (2014). Bisexual, pansexual, queer: Non-binary identities and the sexual borderlands. Sexualities, 17(1/2), 63-80. doi: 10.1177/1363460713511094

Chmielewski, J. \& Yost, M. (2013). Psychosocial influences on bisexual women's body image: Negotiating gender and sexuality. Psychology of Women's Quarterly, 37(2), 224-41. doi: 10.1177/0361684311426126

Coontz, S. (2005). Marriage: A history. New York: Penguin.

Daly, S.J. (2018). A rock and a hard place: A hermeneutic phenomenological exploration into the lived experience of bisexual women in monogamous relationships. $\mathrm{PhD}$ thesis, University of Huddersfield.

Daly, S.J., King, N., \& Yeadon-Lee, T. (2018). 'Femme it up or dress it down': Appearance and bisexual women in monogamous relationships. Journal of Bisexuality, 18(3), 257-77. doi: 10.1080/15299716.2018.1485071

Diamond, L. (2008). Sexual fluidity: Understanding women's love and desire. London: Harvard University Press.

Edmunds, J., \& Turner, B.S. (2005). Global generations: Social change in the twentieth century. The British Journal of Sociology, 56(4), 559-77. doi: 10.1111/ j.14684446.2005.00083

Eliason, M. (2000). Bi-negativity. Journal of Bisexuality, 1(2/3), 137-54. doi: 10.1300/ J159v01n02_05 


\section{Sarah Jane Daly}

Erens, B., McManus, S., Prescott, A., \& Field, J. (2003). National survey of sexual attitudes and lifestyles II. Retrieved from www.natsal.ac.uk/media/2083/reference_tables_and_summary_report.pdf

Fahs, B. (2009). Compulsory bisexuality? The challenges of modern sexual fluidity. Journal of Bisexuality, 9(3/4), 431-49. doi: 10.1080/15299710903316661

Finn, M.D. (2012). Monogamous order and the avoidance of chaotic excess. Psychology \& Sexuality, 3(2), 123-36. doi: 0.1080/19419899.2011.551834

Fisher, H. (2010). The new monogamy: Forward to the past. The Futurist, 44(6), 26-28.

Flanders, C.E., Dobinson, C., \& Logie, C. (2015). "I'm never really my full self": Young bisexual women's perceptions of their mental health. Journal of Bisexuality, 15(4), 454-80. doi: 101080/15299716.2015.1079288

Giddens, A. (1992). The transformation of intimacy. Cambridge: Polity Press.

Goodson, I.F. (2001). Social histories of educational change. Journal of Educational Change, 2(1), 45-63. doi: 10.1023/A:101150812

Gotta, G., Green, R.J., Rothblum, E., Soloman, S., Balsam, K., \& Swartz, P. (2011). Heterosexual, lesbian, and gay male relationships: A comparison of couples in 1975 and 2000. Family Processes, 50(3), 353-76. doi: 10.1111/ j.1545-5300.2011.01365

Green, A.I., Valleriani, J. \& Adam, B. (2016). Marital monogamy as ideal and practice: The detraditionalization thesis in contemporary marriages. Journal of Marriage and the Family, 78(2), 416-30. doi: 10.1111/jomf.12277

Hartman, J.E. (2006). Another kind of chilly climate: The effects of lesbian separatism on bisexual women's identity and community. Journal of Bisexuality, 5(4), 61-76. doi: 10.1300/J159v05n04_06

Hartman-Linck, J.E. (2014). Keeping bisexuality alive: Maintaining bisexual visibility in monogamous relationships. Journal of Bisexuality, 14(2), 177-93. doi: 10.1080/15299716.2014.903220

Hayfield, N. (2011). Bisexual women's visual identities: A feminist mixed-method exploration. PhD thesis, University of the West of England.

Heaphy, B., Donovan, C., \& Weeks, J. (2004). A different affair? Openness and nonmonogamy in same sex relationships. In J. Duncombe., K. Harrison., G. Allan \& D. Marsden (Eds.), The state of affairs: Explorations in infidelity and commitment (pp. 167-86). London: Routledge.

Horne, S. \& Zimmer-Gembeck, M.J. (2006). The female sexual subjectivity inventory: Development and validation of a multidimensional inventory for late adolescents and emerging adults. Psychology of Women Quarterly, 30(6), 12538. doi: 10.1111/j.1471-6402.2006.00276.x

Jones, R.L. (2016). Sexual identity labels and their implications in later life: The case of bisexuality. In E. Peel, \& R. Harding. (Eds.), Aging and sexualities: Interdisciplinary perspectives (pp. 97-118). Farnham: Ashgate.

Klesse, C. (2006). Polyamory and its "others": Contesting the terms of nonmonogamy. Sexualities, 9(5), 565-85. doi: 10.1177/1363460706069986

Klesse, C. (2007). The spectre of promiscuity: Gay male and bisexual nonmonogamies and polyamories. Aldershot: Ashgate.

Lahti, A. (2015). Similar and equal relationships? Negotiating bisexuality in an enduring relationship. Feminism \& Psychology, 25(4), 431-48. doi: 10.1177/ 0959353515574786 
Maliepaard, E. (2017). Bisexuality in the Netherlands: Connecting bisexual passing, communities, and identities. Journal of Bisexuality, 17(3), 325-48. doi: 10.1080/ 15299716.2017.1342214

Moors, A.C., Matsick, J.L., \& Schechinger, H.A. (2017). Unique and shared relationship benefits of consensually non-monogamous and monogamous relationships. European Psychologist, 22(1), 55-71. doi: 10.1027/1016-9

Moss, A. (2012). Alternative families, alternative lives: Married women doing bisexuality. Journal of GLBT Family Studies, 8(5), 405-27. doi: 10.1080/ 1550428X.2012.729946

Namaste, K. (1994). The politics of inside/out: Queer theory, post-structuralism, and a sociological approach to sexuality. Sociological Theory, 12(2), 220-31. doi: $10.2307 / 201866$

Oosterhuis, H. (2012). Sexual modernity in the works of Richard Von Krafft-Ebing and Albert Moll. Medical History, 56(2), 133-55. doi: 10.1017/mdh.2011.30

Pieper, M., \& Bauer, R. (2005). 'Mono-normativity: Poly-desire and consensual non-monogamous relationship'. Paper presented to International Conference on Polyamory and Mono-normativity, University of Hamburg, 5-6 November. Retrieved from www.wiso.uni-hamburg.de/index.php?id1/43495.

Roberts, T.S., Horne, S.G., \& Hoyt, W.T. (2015). Between a gay and a straight place: Bisexual individuals' experiences with monosexism. Journal of Bisexuality, 15(4), 554-69. doi: 10.1080/15299716.2015.1111183

Rodríguez-Rust, P.C. (2000). Bisexuality: A contemporary paradox for women. Journal of Social Issues, 56(2), 205-21. doi: 10.1111/0022-4537.00161

Rust, P.C. (1995). Bisexuality and the challenge to lesbian politics: Sex, loyalty, and revolution. New York: New York University Press.

Rust, P.C. (2003). Monogamy and polyamory: Relationship issues for bisexuals. In L.D. Garnets \& D.C. Kimmel (Eds.), Psychological perspectives on lesbian, gay, and bisexual experiences (pp. 475-96). New York: Columbia University Press.

Savoia, P. (2010). Sexual science and self-narrative: Epistemology and narrative technologies of the self between Von Krafft-Ebing and Freud. History of the Human Sciences, 23(5), 17-41. doi: 10.1177/0952695110375040

Stein, A., \& Plummer, K. (1994). I can't even think straight: Queer theory and the missing sexual revolution in sociology. Sociological Theory, 12(2), 178-87. doi: $10.2307 / 201863$

Summerfield, P. (1994). Women in Britain since 1945: Companionate marriage and the double burden. In J. Obelkevich \& P. Catterall (Eds.), Understanding post-war British society (pp. 58-72). London: Routledge.

Szasz, T. (1980). Sex: Facts, frauds and follies. Oxford: Blackwell.

Tolman, D. (2002). Dilemmas of desire: Teenage girls talk about sexuality. Boston, MA: Harvard University Press.

Toft, A. \& Yip, A.K.T. (2018). Intimacy negotiated: The management of relationships and the construction of personal communities in the lives of bisexual women and men. Sexualities, 12(2), 233-50. doi: 10.1177/1363460716679793

Valentine, G. (1999). Doing household research: Interviewing couples together and apart. Royal Geographical Society, 31(1), 67-74. doi: 10.1111/j.1475-4762.1999

Von Krafft-Ebing, R. (1894). Psychopathia sexualis: A medico-forensic study. New York: Rebmana. 


\section{Sarah Jane Daly}

Vrangalva, Z., Bukberg, R.E., \& Rieger, G. (2014). Birds of a feather? Not when it comes to sexual permissiveness. Journal of Social and Personal Relationships, 31(1), 93-113. doi: 10.1177/0265407513487638

Warner, M. (1999). The trouble with normal: Sex, politics, and the ethics of queer life. New York: The Free Press.

Wiley, S. \& Deaux, K. (2010). The bicultural identity performance of immigrants. London: Blackwell. 